\title{
Accounting for outcomes: Lies, damned lies, and statistics
}

\author{
Robert M. Sade, MD, ${ }^{a}$ and Andrea Boan, $\mathrm{PhD}^{\mathrm{b}}$
}

\footnotetext{
From the ${ }^{\mathrm{a} D i v i s i o n}$ of Cardiothoracic Surgery, Department of Surgery, and ${ }^{\mathrm{b}}$ Division of Developmental Behavioral Pediatrics, Departments of Pediatrics, and Neurology and Public Health Sciences, Medical University of South Carolina, Charleston, SC.

Disclosures: R.M.S. was supported by the South Carolina Clinical and Translational Research Institute, Medical University of South Carolina Clinical and Translational Science Award No. UL1TR001450. The contents are solely the responsibility of the authors and do not necessarily represent the official views of the National Center for Advancing Translational Science of the National Institutes of Health. A.B. has nothing to disclose with regard to commercial support.

Received for publication Nov 30, 2016; accepted for publication Dec 6, 2016; available ahead of print Jan 5, 2017. Address for reprints: Robert M. Sade, MD, Division of Cardiothoracic Surgery, Department of Surgery, Medical University of South Carolina, 114 Doughty St, MSC 295, Suite 277, Charleston, SC 29425 (E-mail: sader@ musc.edu).

J Thorac Cardiovasc Surg 2017;153:1212-3

$0022-5223 / \$ 36.00$

Copyright $(\underset{2016}{ }$ by The American Association for Thoracic Surgery

http://dx.doi.org/10.1016/j.jtcvs.2016.12.009
}

Starnes ${ }^{1}$ presents an enlightening discussion of the benefits and risks of disclosing personal performance data. In our opinion, the critical ethical issue is reliability of the mortality and morbidity rates of an individual surgeon. Starnes ${ }^{1}$ describes confounding issues in making comparisons with either database outcomes or journal reports of outcomes, such as misleading mortality rates owing to poor accounting for comorbidities and other risk factors, unreliable risk adjustment models, and choice of conflicting databases.

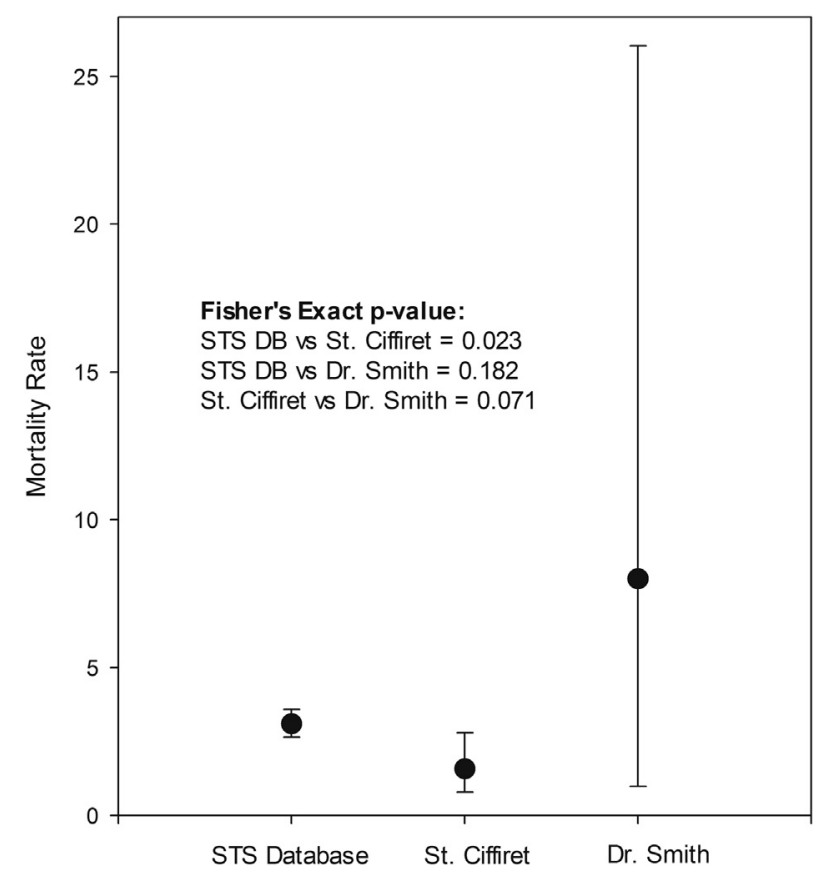

FIGURE 1. Mortality rates for esophageal cancer surgery. These confidence intervals display the overlap between mortality rates after esophageal cancer surgery, comparing results from the Society of Thoracic Surgeons General Thoracic Surgery Database (STS DB), St Cifferet surgeons, and hypothetical doctor Andrea Smith.

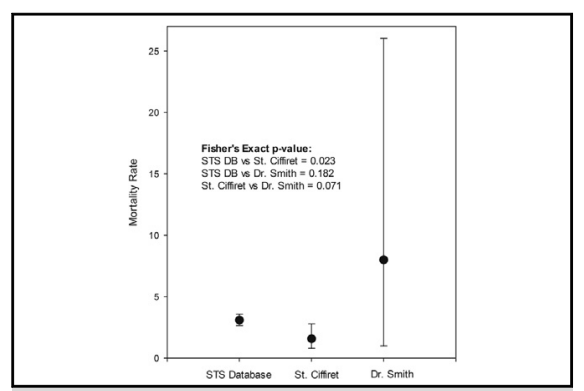

Confidence intervals convey the uncertainties of comparing outcome data.

\section{Central Message}

$\overline{\text { Surgeons are under no obligation to provide pa- }}$ tients with raw numbers of operations done or how their results compare with those of others. To do so would misinform and mislead patients.

See Article page 1209.

Even if these confounding issues did not exist, the problem of the statistical meaning of a surgeon's outcomes remains. Starnes observes that surgeons must "know what our true outcomes are,"1 but how do we know what are our true outcomes and how they compare with others? A $P$ value provided by statistical tests has little meaning, especially if the numerator is small. ${ }^{2} \mathrm{~A}$ more accurate understanding of a surgeon's true mortality rate can be gained from comparison of confidence intervals (CIs) of the surgeon's results compared with CIs derived from database or other reported outcomes. The mortality rate calculated from a surgeon's results is merely an estimate of the true value, which actually lies somewhere within the CI. CIs provide an understanding of the precision around the estimated rate; the $95 \%$ CI indicates that we can be $95 \%$ sure that the true rate lies within that range.

This idea can be illustrated with data from the Society of Thoracic Surgeons (STS) General Thoracic Surgery Database. Between July 2011 and June 2014, the mortality rate for esophageal cancer surgery was 3.1\% (170 hospital deaths in the collected series of 5494 patients). Imagine that a hypothetical doctor, Andrea Smith, has performed 25 such operations and 2 patients died, a mortality rate of $8 \%$, more than 2.5 times higher than the STS database rate. Across town, surgeons at St Ciffiret have performed 700 operations with 11 deaths $(1.6 \%$, half the STS rate). Should Smith inform her patient of these rates and offer referral to St Ciffiret where the mortality rate is 5 times lower than hers? 
We know with $95 \%$ certainty that the STS surgeons' true mortality rate for esophageal cancer operations is between 2.65 and 3.59 (95\% CI) (see Figure 1). Smith's true rate is 0.98 to 26.03, whereas St Cifferet's rate is 0.79 to 2.79. St Cifferet's results are probably better than the STS rate, but Smith's true rate substantially overlaps both of the others, so we do not know with a reasonable degree of certainty whether her mortality rate is better or worse than the other 2 measures.

Smith is under no obligation to provide her patient with esophageal cancer with raw numbers of operations done or how her results compare with those of others, in our view. To do so would misinform and mislead the patient. Smith's recital of the operative risks to her patient should include mortality risk, but only in general terms that can be readily understood by this particular patient.

\section{References}

1. Starnes SL. The American Association for Thoracic Surgery 2016 ethics forum preoperative disclosure: in all honesty, my results.... J Thorac Cardiovasc Surg. 2017:153:1209-11.

2. Baker M. Statisticians issue warning on $P$ values. Nature. 2016;531(7593):151. 